\title{
Numerical Simulation of Solid-Liquid Two-Phase Flow and Wear Characteristics in Rotary Liner Hanger Bearing
}

\author{
Weiqing $\mathrm{Li}^{*}$ and Ying Wang \\ School of Engineering and Technology \\ China University of Geosciences (Beijing) \\ Beijing, 10083, China \\ *Corresponding author
}

\begin{abstract}
The sand of drilling flow that enters into rotary liner hanger bearing will wear the bearing, which will reduce its service life seriously. Applying the fluid software, this paper simulated the wear characteristic of fluid domain inside the bearing. Based on the Finnie wear model, this paper analyzed the erosion rate of bearing with different particle size and density of drilling fluid. The results show that, when the density is constant, the erosion rate decrease with the increase of particle size. On condition that the particle size is constant, when the density of drilling fluid is low, the erosion rate increases with the increase of the density until the density reaches a certain large value, then the erosion rate decreases firstly and increases later with the increase of the density. The erosion rate is the lowest when the particle size is $0.07 \mathrm{~mm}$ and density is $1960 \mathrm{~kg} / \mathrm{m}^{3}$ from the simulation result.
\end{abstract}

Keywords-solid-liquid two-phase flow; erosion wear; numerical simulation

\section{INTRODUCTION}

Nowadays, rotary liner hanger bearing in China is not able to meet the drilling engineering of ultra-deep wells and complex wells because of its complex work conditions such as high temperature, high pressure, heavy load and wear of drilling fluid and etc.

To solve this problem, some scholars have done some research. Jianchong Wang used ANSYS software to simulate the static analysis of the bearing and obtained the maximum shear stress located at the two ends of the roller. Then, he changed the structure of the washer and the roller's big end to improve the stress concentration in the seal groove, but that has not solved the stress concentration phenomenon of the roller ends [1] [2]. Zhijun Niu did some modification of the roller, which effectively solved the stress concentration phenomenon of the roller ends. The simulation result show that roller modification increase the carrying capacity of the roller and improved the bearing life by delaying or avoiding the breakage of the roller ends [3] [4]. Yu Wang applies ABAQUS software to design and analyze the bearing's seal structure in order to prevent the sand of drilling fluid enter into the bearing and reduce the bearing wear [5].

In fact, no matter how well the bearing seal is, the sand in drilling fluid will enter into the bearing inevitably. The sand will cause micro-crack on the bearing surfaces. If the wear continues, micro-cracks will expand and eventually lead to bearing failure. According to an incomplete statistics, $80 \%$ of mechanical part failure is due to wear and $1 / 2$ of the overall wear loss is because of abrasive wear. Previous research focuses on changing the bearing structure so as to increase the bearing capacity and improve the sealing effect. This paper focuses on simulating the drilling fluid performance in the bearing and obtains the optimal drilling fluid parameters that have the minimal wear rate. There are many factors that influence on the performance of drilling fluid. This paper mainly study how the particle size and density of drilling fluid influence on bearing wear rate. The result is able to be the basis of selecting the particle size and density of drilling fluid within the scope of the permit, which has the lowest erosion rate to improve the bearing service life.

\section{MATHEMATICAL MODEL}

\section{A. A Method of Kinematics of Liquid-Solid Two Phase Flow}

In engineering, the Euler-Lagrange method is generally used to predict of sparse liquid-solid two-phase flow. The fluid as a continuous medium is described by Euler method and solid particles as discrete system is described by the Lagrange method. In order to consider the effect of fluid turbulent on the particle, this paper uses the particle trajectory model.

Fluid phase adapt Reynolds average model which NavierStokes equation is averaged with Reynolds method and get the Reynolds average equation. But the average turbulence equation includes pulsating second-order relevant quantity. In order to close turbulence equation, the closed model needs to be introduced. Different closed models will produce different turbulence models. This paper select $\mathrm{k}-\varepsilon$ closed model because it takes the historical effect between different turbulence statistics into consideration.

The following assumptions were made for particle trajectory model of discrete phase [6],

1) There are slips between sand particles and fluid.

2) Only the quality of sand particles itself will change with time, but sand particles do not affect each other. 
3) All the sand particles slip according to their own tracks from the initial positions. The velocity and quality of sand particles are able to be gotten along the tracks.

This kind of model has a clear physical concept. It is able to describe the complex particle movement simply. Therefore, this paper select this model to describe the sparse liquid-solid two phase flow.

\section{B. Surface Wear Rate Model}

In flow system, erosion wear is a very complicated process. The factors affecting wear mainly include four aspects: fluid mechanics factor, electrochemical factor, solid phase particles factor and material factor. This paper mainly study solid phase particles factors. The amount of wear is generally expressed by erosion rate in ANSYS. It is defined as cutting material quality at material surface per unit time and per unit area. When particles hit the wall, the wall absorbs a part of energy, which will cause the particle's energy loss. This characteristic is described by vertical and parallel coefficient in ANSYS.

In this paper, the wear model applies Finnie micro cutting wear model (1) [7]:

$$
\begin{cases}E=K F(\alpha) V_{P}^{n} & \tan \alpha>\frac{1}{3} \\ F(\alpha)=\frac{1}{3} \cos ^{2} \alpha & \tan \alpha \leq \frac{1}{3} \\ F(\alpha)=\sin (2 \alpha)-3 \sin ^{2} \alpha & \end{cases}
$$

$\mathrm{K}$-Constant which is related to the particle properties.

$\alpha$ _ Attacking angle that the particles attack the wall.

$F(\alpha)$ _Attacking angle function.

$V_{P}$ _Relative velocity between sand particle and the wall.

$\mathrm{n}$-Speed index. For the sand particles, its value is 2 .

\section{NUMERICAL SIMULATION}

\section{A. Simulation Model}

This paper applied a full complement tapered roller bearing from a patent of Ma Lanrong [8]. Firstly, the threedimensional parametric solid model of bearing was built by three-dimensional modeling software Solidworks. Because of the symmetry of the bearing, this paper selected $1 / 42$ model as the calculation model. In order to clearly see the movement condition of the sand particles between the rollers, this paper substitute two half of the roller for the whole roller as the research object. The three-dimension modeling model is shown in Figure 1. This paper mainly studied the wear conditions of drilling fluid in the bearing. So, the fluid domain is internal clearance of bearing roller, retainer ring, shaft ring and seat. The research is based on assumption that the sand particles have entered into the bearing, so the fluid domain that express the internal clearances between retainer ring, adjusting ring and sealing ring were ignored. Figure 2 showed the fluid domain model.

The model as shown in Figure 2 was imported into ANSYS CFX to analysis liquid-solid two phase flow. The

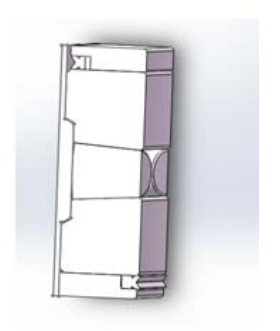

FIGURE I. THREE-DIMENSION MODELING MODEL

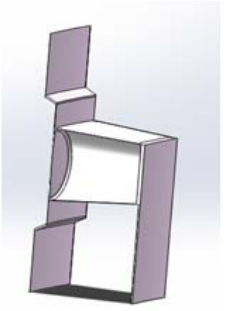

FIGURE II. FLUID DOMAIN

meshing was done by ICEM software. Because the internal clearance between retainer ring, shaft ring, and seat ring is very small, tetrahedron mesh was adopt. The total number of grid is 170291 .

\section{B. Basic Assumptions}

In order to implement numerical calculation of solid liquid two phase flow in bearing internal better, some assumptions for computational fluid domain were made.

1) Fluid phase (the main ingredient is water) is a Newtonian fluid which is continuous and incompressible fluid.

2) The sands are spherical particles of uniform particle size and density.

3) Physical property of each phase is constant, regardless of the phase change.

4) Solid phase and liquid phase have the same speed and they are evenly distributed each other.

5) The internal flow of bearing reaches a full turbulent state.

\section{Boundary Conditions}

\section{1) Inlet boundary condition}

Inlet boundary condition is the import speed condition of the drilling fluid. The inlet velocity condition was obtained according to the inlet flow that drilling fluid flush debris and inlet cross-sectional area. Fluid property is set to the subsonic because the fluid belongs to multiphase flow problem. Mass and momentum adapt Cart. vel. component. The direction of inlet velocity is perpendicular to the import surface. The speed along $\mathrm{x}$ axis and $\mathrm{y}$ axis are all zero and speed along $\mathrm{z}$ axis is obtained from Wprof's empirical formula (2) [9].

$$
W_{\text {prof }}=W_{\max }\left(1-\frac{r}{R_{\max }}\right)^{\frac{1}{7}}
$$


$R_{\text {max }}$ - The largest radius of inlet face, mm. According to the design drawing, it is $116 \mathrm{~mm}$.

$r$ - The vertical distance between the research point and the center axes of the inlet surface, $\mathrm{mm}$.

$W_{\text {prof }}$ - The point speed whose the distance between the point and the central axis of inlet face is $\mathrm{r}, \mathrm{m} / \mathrm{s}$.

$W_{\max }$ - The maximum speed on the central axis of the inlet face, $\mathrm{m} / \mathrm{s}$. It is $0.7 \mathrm{~m} / \mathrm{s}$ in this paper by calculating based on the flow and cross-sectional area.

\section{2) Outlet boundary condition}

Outlet boundary condition is set to be opening. The pressure is $120 \mathrm{MPa}$ according to 5000 meters well [10].

\section{3) Wall condition}

The walls are set to no-slip walls. Considering the relativity of speed, the wall that contact with the axis and the wall of retainer ring are set to be rotation speed, the rotational speed are all $25 \mathrm{r} / \mathrm{min}$ according to the drilling condition. The rotational speed of the rollers is $337.4556 \mathrm{r} / \mathrm{min}$ according to the calculation result based on pure rolling. The roughness of all of the Surfaces is set according to the drawing.

\section{RESULTS AND DISCUSSION}

Wear in the flow system is a very complicated process. The main factors of affecting wear include the fluid mechanics factors, electrochemical factors, solid phase particles factors and material factors [11]. In this paper, we mainly study the factors of the density of drilling fluid and the particle size of the solid phased particles, which is the main influence on rotary liner hanger bearing erosion.

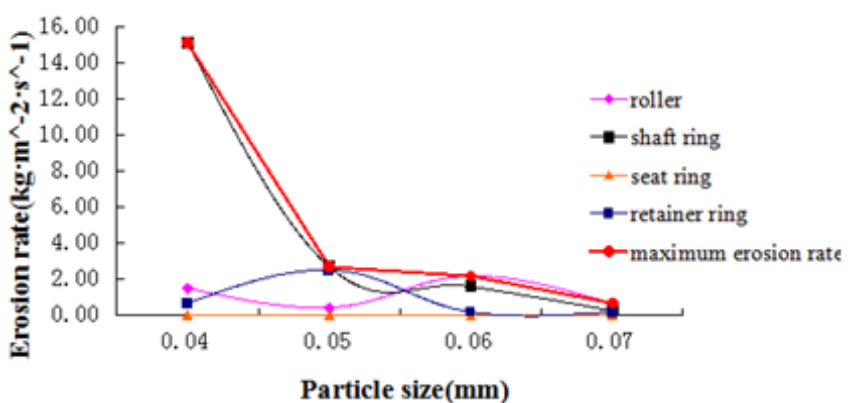

FIGURE III. MAXIMUM EROSION RATE WITH DIFFERENT PARTICLE SIZE OF THE VARIOUS PARTS OF THE BEARING

\section{A. Particle Size}

This paper simulated the particle size influence when the density of drilling fluid is a constant. Several different particle sizes were taken. When the density of drilling fluid is $1960 \mathrm{~kg} / \mathrm{m}^{3}$, different particle sizes were taken $0.040 \mathrm{~mm}$, $0.050 \mathrm{~mm}, 0.060 \mathrm{~mm}$ and $0.070 \mathrm{~mm}$ according to the sizes of current drilling fluid.

Figure 3 shows the erosion rate curve of roller, retainer ring, shaft ring and seat ring with different particle sizes and the maximum erosion rate curve which is obtained by considering the maximum erosion rate on the whole bearing with different particle sizes. Each curve of roller, shaft ring, retainer ring and seat ring has a fluctuation because the particle trajectory is stochastic [6]. However, the maximum erosion rate curve shows that it decreases with the increase of particle size when the density is certain. Because particle motion needs some energy, the bigger the particle is, the greater the energy required. Therefore, the bigger the particle is, the smaller the speed of the impacting wall is, which leads to that the erosion rate is smaller when the particle size is bigger.

The simulation result in this paper is that the erosion rate has the minimum value when the particle size is $0.07 \mathrm{~mm}$. Therefore, one of the methods that improve the bearing service life is setting the particle size of drilling fluid to the maximum particle size within the scope of the permit, which is able to reduce the bearing erosion rate.

Figure 3 also shows that the erosion rate of roller and shaft ring is larger than the retainer ring and seat ring. When the particle size is $0.07 \mathrm{~mm}$, the maximum wear part of the bearing is the roller. Figure 4 shows the location of maximum erosion rate on the roller.

When the particle sands enter into the bearing internal, roller, retainer ring, shaft ring and seat ring form abrasion. The surfaces of bearing will cause scratches and micro-cutting because the stress applied on the sand is less than their crushing strength. The forces acting on the surface of the bearing are able to be decomposed into normal forces and tangential forces. Normally forces will press the sand into the bearing's surface and generate indentation on the bearing's surface. Tangential forces will push the sand forward and sand will shear, furrow and cut the bearing's surface like a knife, but the cutting depth and width are small. When the sand touches the bearing surface continually, the bearing's surface under the action of cyclic contact stress will form micro cracks. Micro cracks expand gradually and is expected to result in flaking and bearing failure eventually.

\section{B. Density of Drilling Fluid}

Particle size simulation result shows that the best particle size is $0.070 \mathrm{~mm}$. This paper set the particle size to be $0.070 \mathrm{~mm}$ when the influence of the density of drilling fluid was

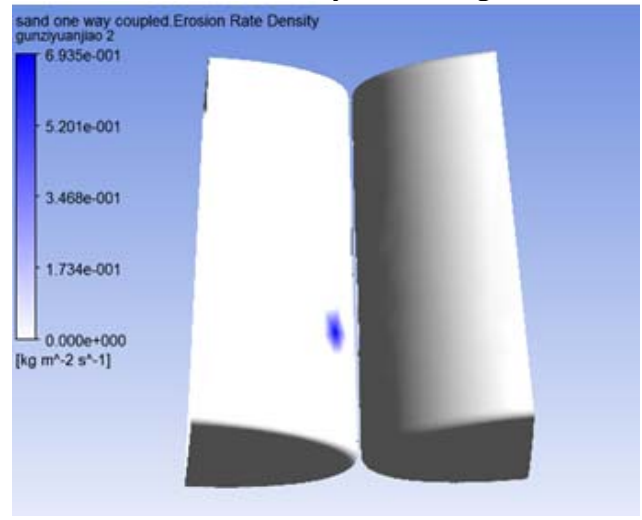

FIGURE IV. EROSION RATE OF ROLLER 


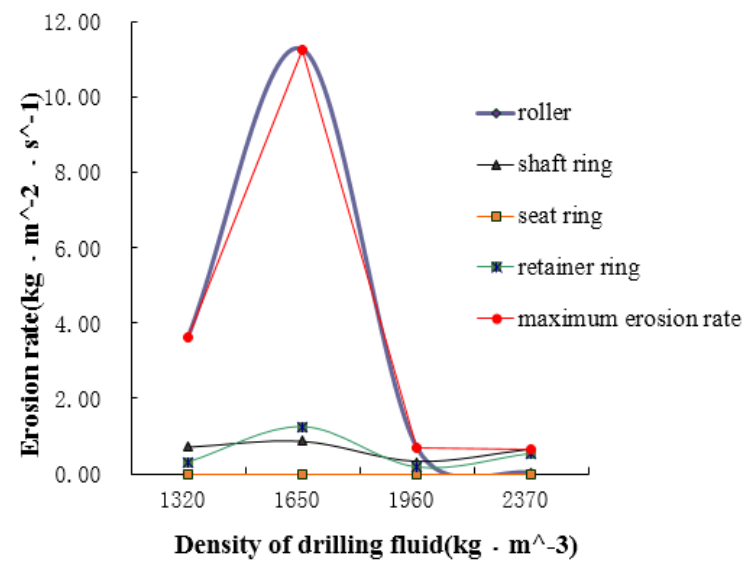

FIGURE V. RELATIONSHIP BETWEEN THE VARIOUS PARTS OF THE BEARING MAXIMUM EROSION RATE AND THE DENSITY OF DRILLING

studied. Drilling fluid's density were taken $1320 \mathrm{~kg} / \mathrm{m}^{3}$, $1650 \mathrm{~kg} / \mathrm{m}^{3}, 196 \mathrm{~kg} / \mathrm{m}^{3}$ and $2370 \mathrm{~kg} / \mathrm{m}^{3}$ [10] [12]. Figure 5 is the simulation results of the maximum erosion rate of bearing roller, retainer ring, shaft ring and seat ring.

Figure 5 shows that the erosion rate of roller is the most seriously, followed by shaft ring, retainer ring and seat ring. The curve of the maximum erosion rate shows that the maximum erosion rate is the lowest when the drilling fluid density is $1960 \mathrm{~kg} / \mathrm{m}^{3}$. It also shows that, when the particle density is small, the rate increase with the increase of the density of the drilling fluid until the density reaches a certain large value. After the certain large value, the erosion rate begins to decrease than increase with the increase of density of the drilling fluid. The conclusion of this paper is the same as the explaining of one book [13]. Therefore, numerical simulation in this paper is correct and is able to be the basis of design drilling machine.

Figure 5 also show that, when particle size is constant and the densities of drilling fluid are different, almost all of the serious wear parts are at the roller. For example, Figure 4 shows that, when the density is $1960 \mathrm{~kg} / \mathrm{m}^{3}$, the biggest wear parting at the roller of bearing.

\section{CONCLUSIONS}

The following conclusions can be drawn based on the analysis and discussions presented.

A. The Erosion Rate is Associated With Particle Size: When the density of drilling fluid is constant, the erosion rate decrease with the increase of particle size. In this paper, when the particle size is $0.07 \mathrm{~mm}$, the minimum erosion rate is obtained. Therefore, this simulation result is able to be the basis of selecting the particle size of the drilling fluid that applies in rotary liner hanger bearing.

B. The Erosion Rate is Associated With the Density of Drilling Fluid: When the density of drilling fluid is small, the erosion rate is increased with the increase of the density, until the density reaches a certain large value, the erosion rate is reduced then increase with the increase of the density.
Therefore, the maximum erosion rate is the lowest when the drilling fluid density is $1960 \mathrm{~kg} / \mathrm{m}^{3}$.

C. The Location of Maximum Erosion Rate Has a Certain Regularity: With the change of particle size and density of drilling fluid, almost all of the biggest erosion rate appears at the roller. Therefore, the roller of the bearing is the easy failure parts. This result provides some direction for improving the bearing structure.

\section{ACKNOWLEDGMENT}

This project was supported by the Fundamental Research Funds for the Central Universities (265201304). This project also thanks Luoyang Bearing Science \& Technology Co., Ltd who provide us with test data so that we have the reference of the simulation research.

\section{REFERENCES}

[1] J. C. Wang, "Finite element analysis of rotary liner hanger bearing based on ANSYS-Workbench,” [D]. Beijing: China University of Geosciences, 2014.

[2] Weiqing Li, Jiangchong Wang, “Analysis of thermo-mechanical coupling characteristics and structural design of rotary liner hanger bearing in ultra-deep well drilling,” Proceedings of IMETI 2014. P33-39, (Orlando Florida, USA), July 15-18, 2014.

[3] Z. J. Niu, "Tapered roller modification theory research and performance optimization of rotary liner hanger bearing," [D]. Beijing: China University of Geosciences, 2015.

[4] W.Q. Li, Z.J. Niu and G.S. Chen, "Research on the modification technology for tapered roller bearing of rotary liner hanger in ultra-deep well drilling," in press. International Conference on Mechanical and Automation Engineering.

[5] Yu Wang, "Seal performance research of deep well drilling rotary liner hanger bearing,” [D]. Beijing: China University of Geosciences, 2015.

[6] Y. L. Wu, X. L. Tang, "Hydraulic machinery cavitation and solid-liquid two-phase hemodynamic," [M]. Beijing: Chinese hydropower press, 2007.

[7] Finnie I. "Erosion of surface by solid particles," [J].Wear, 1960, vol.3, pp.87-103.

[8] China Petroleum \& Chemical limited company, China Petroleum \& Chemical limited company engineering technology research institute, “A kind of rotary liner hanger bearing,” [P].China: CN201826788U, 2011, 05, 11.

[9] Y. Z. Li, M. S. Yuan, "Hydromechanics," [M]. Beijing: Higher education press, 2008.

[10] Y. Q. Jiao, “Research on deep well cement slurry,” [D]. Beijing: China University of Petroleum, 2007.

[11] Z. Xu, "Research on the erosion-corrosion behavior of P110 steel in liquid-solid two-phase flow,” [D]. 2011.

[12] L. R. Ma, C. H. Guo, D.K. Yang, and J. Z. Su, "Key technology study and performance test of rotating liner cementing," [M]. Petroleum mining machinery, 2009, vol. 38:pp.67-70.

[13] M. Qiu, Y. M. Qian, “Tribology principle and design,” [M]. Beijing: National defence industry press, 2013. 